ECCOMAS Proceedia
COMPDYN 2021

$8^{\text {th }}$ ECCOMAS Thematic Conference on Computational Methods in Structural Dynamics and Earthquake Engineering M. Papadrakakis, M. Fragiadakis (eds.) Streamed from Athens, Greece, 28 - 30 June 2021

\title{
SEISMIC VULNERABILITY OF SHALLOW UNDERGROUND CAVITIES IN SOFT ROCK
}

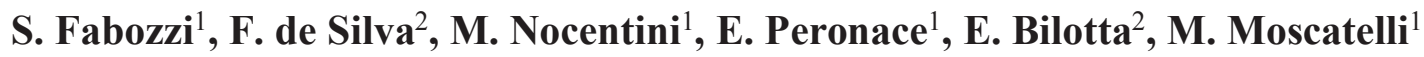 \\ ${ }^{1}$ Institute of Environmental Geology and Geoengineering - National Research Council of Italy \\ Area della Ricerca Roma, 1, Monterotondo RM, Italy \\ \{stefania.fabozzi,marco.nocentini,edoardo.peronace,massimiliano.moscatelli\}@igag.cnr.it \\ ${ }^{2}$ Department of Civil, Architectural \& Environmental Engineering - University of Naples Federico II \\ Via Claudio 21 Napoli, Italy \\ \{filomena.desilva,emilio.bilotta\}@unina.it
}

\begin{abstract}
The instability risk of underground cavities is issue of concern particularly for areas densely urbanized as the case of many historical centers in Italy. Among the possible causes of the cavity damages up to collapse, the proposed work considers a particular triggering factor that is the dynamic loading induced by an earthquake. Thus, the seismic vulnerability of shallow cavities in soft rock is addressed by proposing a methodology based on an extensive parametric two-dimensional finite element analysis. The proposed methodology is extended to a significant number of realistic cases, considering the effect of the variability of some predisposing and triggering factors on the cavity stability like roof thickness and cavity width, presence of overburden on the top of the rock layer, seismic signal intensity. The seismic vulnerability of the studied cases is assessed through the minimum Factor of Safety calculated during the whole length of the dynamic analysis. Finally, the results of the parametric study are rearranged into 'seismic stability charts for cavities in soft rock' proposed to be adopted as preliminary level of screening, to assess the seismic vulnerability of shallow underground cavities in soft rock. The results of screening enable to identify the critical zones that need a detailed analysis, in consideration of their possible interaction with above-ground structures, infrastructures and human activities.
\end{abstract}

Keywords: FEM, full dynamic analysis, underground cavities, soft rock, Factor of Safety 


\section{INTRODUCTION}

Shallow underground anthropogenic cavities are frequently spread over the most urbanized areas in many Italian regions whereby their stability represents matter of concern leading to potential risk for buildings, infrastructures, and population. Different causes can induce cavity instability: starting from their excavation, the initial static stability can worsen over time due to an unexpected overloading, water recharge, water table fluctuation and other particular conditions that can result in progressive damage up to the global collapse. Furthermore, seismic actions can represent source of instability for underground cavities as documented by numerical studies in literature $[1,2]$ and historic observations in some Italian database of coseismic effects (CFTI5Med, $\underline{\text { http://storing.ingv.it/cfti/cfti5/ [3]; CEDIT, }}$ http://www.ceri.uniroma1.it/index_cedit.html, [4]).

In the present work we focused our attention on the seismic behavior of cavities, proposing a methodology to assess their stability. The proposal was tested in a specific soft rock type, that is the Neapolitan Yellow Tuff where it is very recurrent to found anthropogenic cavities excavated for different needs during years and with different features (e.g. cavity shape, dimension, cover, other loads). Some studies in the technical literature are dedicated to such cavities, that consider their stability under static and seismic actions $[5,6,7,8,9,10]$.

The proposed methodology, described in detail afterwards, is extended to a significant number of realistic cases, taking into account the variability of some different predisposing and triggering factors of the cavity instability (i.e. the width and depth of cavity, the overburden stress, the intensity of the seismic action). A parametric study via numerical dynamic analyses was conducted in plane strain conditions using the finite element code Plaxis 2D, on simplified rectangular shapes of shallow cavity. The ground shaking was simulated by applying several time histories of acceleration at the base of the numerical model.

The cavity stability was evaluated by assuming the rock cover above the cavity roof as a beam and quantifying the so-called Factor of Safety (FoS) calculated as the ratio between the resistant moment $\left(\mathrm{M}_{\mathrm{r}}\right)$ and the loading moment $\left(\mathrm{M}_{\text {load }}\right)$ in correspondence of the most critical vertical sections. The considered FoS is the lowest one experienced during each shaking. The obtained results are presented and discussed in terms of variation of FoS as a function of the ratio $\mathrm{L} / \mathrm{H}$ (with ' $\mathrm{L}$ ' equal to cavity width and ' $\mathrm{H}$ ' equal to the depth of the cavity roof, or rock cover), of PGA $\mathrm{A}_{\text {input }}$ and of the overburden above the rock cover, $\mathrm{q}$.

Although the analyzed conditions are simplified, the parametric study provides a methodological approach to be adopted as a preliminary level of screening to assess the seismic vulnerability of shallow underground cavities in soft rock. The results of screening enable to identify the critical zones that need a detailed analysis, in consideration of their possible interaction with the above structures, infrastructures and human activities.

\section{METHODOLOGY}

The preliminary stability assessment of underground cavities in soft rock under seismic actions is proposed upon the results of a significant number of parametric two-dimensional Anite-element analyses carried out for realistic cases of underground cavities. A rectangular shape cavity was adopted for the analyses that is, with good approximation, representative of many shallow cavities excavated in soft rock. Therefore, for the specific case of rectangular shallow cavities, the parametric study was built considering: $i$ ) the effect of varying the width of the cavity (L); ii) the effect of stress acting in the rock, by varying the depth of the cavity roof $(\mathrm{H})$ and the entity of the load applied above the rock cover (q); iii) the intensity of the seismic action by varying the PGA and the frequency content of the input signals selected 
among unscaled records of real earthquakes. Table 1 shows all the geometries considered for the analyses: in total 10 geometrical layouts were analysed, defined by varying $\mathrm{H}$ from a minimum of $2 \mathrm{~m}$ up to a maximum of $10 \mathrm{~m}$, and $\mathrm{L}$ from a minimum of $2 \mathrm{~m}$ up to a maximum of $10 \mathrm{~m}$. For each layout, two loading conditions were considered $\left(\mathrm{q}_{1}=50 \mathrm{kN} / \mathrm{m}, \mathrm{q}_{2}=150 \mathrm{kN} / \mathrm{m}\right)$, reaching a total number of cases equal to 20 . The minimum cavity dimensions were selected to obtain a value of the slenderness of the roof, $\mathrm{L} / \mathrm{H}$, higher or at least equal to 1 while the maximum dimensions were set in order to guarantee the static stability of the cavity. The vertical load applied at the model surface intends to simulate the presence of soil layers and fills and above the rock cover and structures or infrastructures at the ground surface.

\begin{tabular}{ccccc}
\hline $\begin{array}{c}\text { layout } \\
\#\end{array}$ & $\begin{array}{c}\mathrm{H} \\
(\mathrm{m})\end{array}$ & $\begin{array}{c}\mathrm{L} \\
(\mathrm{m})\end{array}$ & $\begin{array}{c}\mathrm{L} / \mathrm{H} \\
(-)\end{array}$ & $\begin{array}{c}\mathrm{q}_{1}, \mathrm{q}_{2} \\
(\mathrm{kN} / \mathrm{m})\end{array}$ \\
\hline 1.1 & & 2 & 1 & \\
1.2 & 2 & 5 & 2.5 & \\
1.3 & & 10 & 5 & \\
\hline 2.1 & & 5 & 1 & \\
2.2 & 5 & 10 & 2 & \multirow{2}{*}{50,150} \\
2.3 & & 15 & 3 & \\
2.4 & & 20 & 4 & \\
\hline 3.1 & & 10 & 1 & \\
3.2 & 10 & 15 & 1.5 & \\
3.3 & & 20 & 2 & \\
\hline
\end{tabular}

Table 1: Geometric and loading properties of realistic cavity models.

The variability of the seismic action was considered by varying the peak ground acceleration and the frequency content of the input signals as shown in Table 2: 12 unscaled accelerograms of real earthquakes were extracted from the Italian database ITACA (http://itaca.mi.ingv.it/) and, for the classes with higher energy content, from the international PEER database (https://ngawest2.berkeley.edu/), considering PGA $_{\max }$ values ranging from a minimum of $0.118 \mathrm{~g}$ up to a maximum equal to $0.367 \mathrm{~g}$ and $\mathrm{f}_{\max }$ values ranging from a minimum of $0.51 \mathrm{~Hz}$ up to a maximum equal to $11.26 \mathrm{~Hz}$. The signals were subjected to a bandpass Âltering in the range of $0.1-25 \mathrm{~Hz}$ prior to the seismic response analyses.

Finally, 240 analyses (10 cavity geometries x 2 load conditions x 12 signals) were performed.

Figure 1 shows, as an example, the numerical model implemented in Plaxis 2D for the layout \#3.1 (see Table 1). The cavity was excavated in Neapolitan Yellow Tuff that was modelled with a simple linear elastic-perfectly plastic model with a Mohr-Coulomb failure envelope [5]: the tuff unit weight (" $\mathrm{t}$ ) equal to $16 \mathrm{kN} / \mathrm{m}^{3}$, the cohesion (c') equal to $866 \mathrm{kPa}$, the friction angle (!') equal to $30^{\circ}$, the angle of dilatancy (\$) equal to $0^{\circ}$, the uniaxial compressive strength ( $\mathrm{c}$ ) equal to $3 \mathrm{MPa}$, the Poisson ratio (\#) equal to 0.3 , the Young modulus (E) equal to $2000 \mathrm{MPa}$, a tension cut-off of $\mathrm{t}$ equal to $0.1 \mathrm{c}$.

An amount of viscous damping equal to 5\% was added to the model through the well-known Rayleigh formulation, calibrating the mass and stiffness matrix coefficients by means of the double frequency approach. Moreover, the hysteretic behavior of tuff under dynamic loading was not modelled, given the high linearity threshold measured experimentally by [11]. 


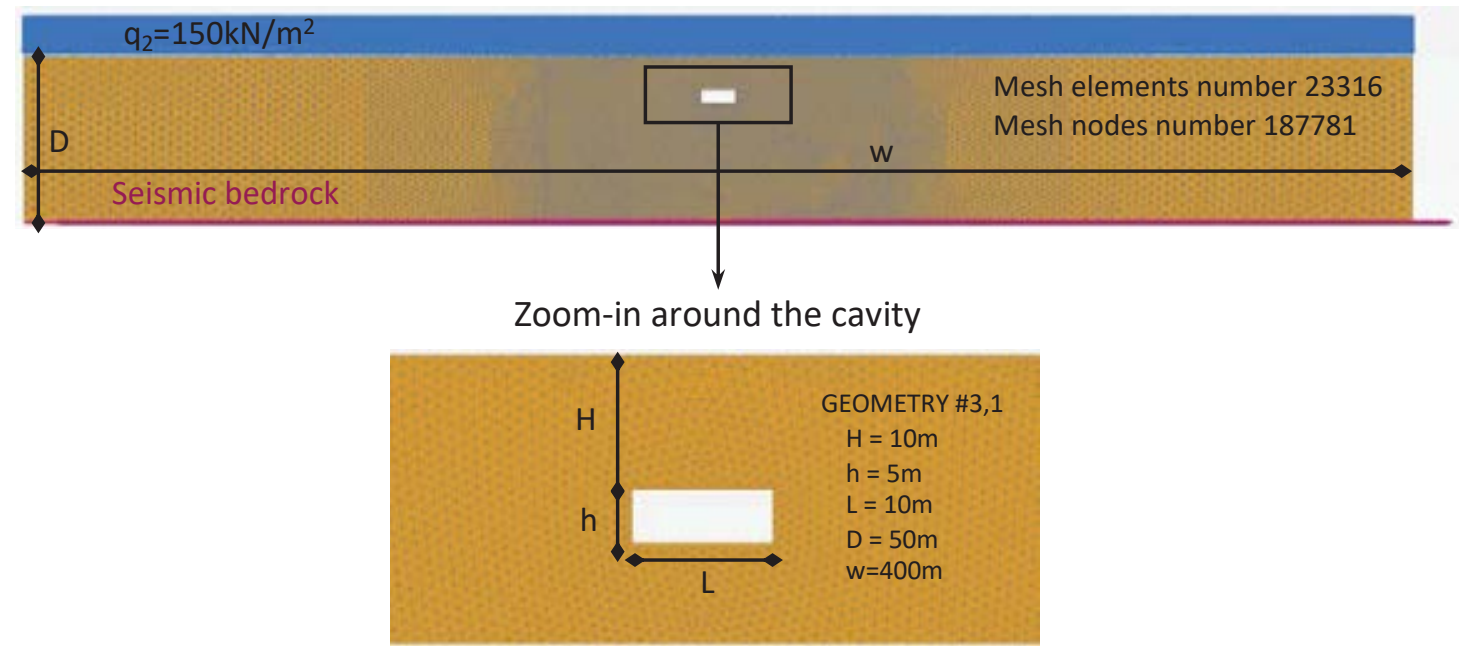

Figure 1: Example of numerical mesh for layout \#3.1 implemented in Plaxis 2D.

\begin{tabular}{lcccc}
\hline \multicolumn{1}{c}{ Event } & \begin{tabular}{c} 
Date \\
\multicolumn{1}{c}{-}
\end{tabular} & $\begin{array}{c}\mathrm{Mw} \\
-\end{array}$ & $\begin{array}{c}\mathrm{PGA}_{\max } \\
(\mathrm{g})\end{array}$ & $\begin{array}{c}\mathrm{f}_{\max } \\
(\mathrm{Hz})\end{array}$ \\
\hline Greece & $07 / 09 / 99$ & 5.8 & 0.118 & 2.33 \\
L'Aquila (Italy) & $09 / 04 / 09$ & 5.4 & 0.146 & 11.26 \\
Southern Italy & $09 / 09 / 98$ & 5.6 & 0.161 & 1.56 \\
Cosenza (Italy) & $25 / 10 / 12$ & 5.0 & 0.182 & 3.48 \\
Central Italy & $26 / 10 / 16$ & 5.4 & 0.192 & 2.91 \\
Central Italy - Visso & $26 / 10 / 16$ & 5.9 & 0.210 & 1.06 \\
Southern Greece & $15 / 09 / 86$ & 4.8 & 0.232 & 1.34 \\
Central Italy - Norcia & $30 / 10 / 16$ & 6.5 & 0.264 & 0.88 \\
Greece & $15 / 10 / 16$ & 5.5 & 0.287 & 2.68 \\
Imperial Valley & $15 / 10 / 79$ & 6.4 & 0.315 & 1.90 \\
Friuli 3 $3^{\text {th }}$ shock (Italy) & $15 / 09 / 76$ & 6.0 & 0.341 & 5.10 \\
Loma Prieta & $18 / 10 / 89$ & 6.9 & 0.367 & 0.51 \\
\hline
\end{tabular}

Table 2: Natural accelerograms selected for the seismic analyses.

The numerical analyses consist of three calculation stages $[12,13]$ :

- first stage: initialization of the initial stress state within the soft rock mass domain;

- second stage: simulation of the cavity excavation by means of the deactivation of the cavity volume. When possible, generally for lower value of $\mathrm{L} / \mathrm{H}$, single step excavation solution was assumed as conservative assumption, while for higher values of $\mathrm{L} / \mathrm{H}$ multiple steps excavation solution were adopted;

- third stage: full dynamic analyses in the time domain, simulating all the selected earthquake recordings in Table 2.

It is worth noting that the same FE mesh used for static analysis (see Fig. 1) was used for the full dynamic analysis. The width of such numerical model in fact, was originally optimized by a series of sensitivity analyses, in order to reach a true free-Āeld condition at the lateral borders and to minimize the in Äuence of vertical boundaries [13]. Also, the mesh was refined to achieve a reliable propagation of the minimum signiĀcant wavelength of the input 
signals [14]. The lateral boundary conditions consist of fixed displacements in the horizontal direction perpendicular to the vertical sides of the mesh in static condition; viscous dashpots are applied during dynamic stages of analysis [14]; the base of the model, $50 \mathrm{~m}$ deep, is fixed both in vertical and in horizontal directions; the nodes at the top surface are free.

The cavity stability was assessed by means of the Factor of Safety (FoS), calculated as the ratio between the ultimate resistant moment $\left(\mathrm{M}_{\mathrm{r}, \mathrm{ULS}}\right)$ corresponding to the achievement of the compressive, c, and tensile, $\mathrm{t}$, strengths in the compression and tensile zones and the loading moment $\left(\mathrm{M}_{\text {load }}\right)$ acting in correspondence of the most critical vertical section of the roof beam and calculated by integrating the horizontal stress component, $\mathrm{xx}$, acting on the considered sections. The FoS $\mathrm{S}_{\text {static }}$ is computed at the end of the second stage of analysis, while $\mathrm{FoS}_{\mathrm{dyn}}$ is computed at the end of the full dynamic analyses at stage three, as the lower value experienced during the dynamic analysis under each input signal.

\section{RESULTS}

Figures 2 and 3 show, for the case of layout \#3.1, the horizontal stress distribution acting around the cavity (assuming negative the compressive stress) in correspondence of three reference sections of the roof beam (central section in red, the right and left sections at pillars edges in green and light blue, respectively) after its excavation and during Loma Prieta earthquake considered as example.

After the cavity excavation (Figure 2), the roof tends to behave as a beam subjected to uniform distributed load, not completely bounded at the edges of the pillars: in the upper portion of the vault, the compression area assumes the typical arched profile over the underlying tension area; the separation curve between the compression and tension zones represents the location of the neutral axes of the different sections of the roof beam that assumes an approximately parabolic shape. Definitely, the central section is stretched in the bottom, in correspondence of the roof cavity extrados, and compressed at the top while the lateral reference sections at the intersection with pillars are totally compressed. Similar behavior was observed also in the other cavity layouts (see Table 1); a tensile zone in correspondence of the lateral section in the upper portion closer to the ground surface has been sometimes calculated for shallower cavities, depending on the roof slenderness (the ratio between the cavity width and cover).

For the proposed example in Figure 2, the horizontal stress distributions in correspondence on the central and the lateral sections produce a value of loading moment equal to $\mathrm{M}_{\text {load,cx }}=3432 \mathrm{kNm}$ and $\mathrm{M}_{\text {load,left=right }}=1144 \mathrm{kNm}$ respectively. By comparing the loading moments with the resistant moment $\mathrm{M}_{\mathrm{r}, \mathrm{ULS}}=13727 \mathrm{kNm}$ of the roof resistant section, $\mathrm{FoS}_{\text {static }}$ equal to 4 and 12 was calculated for the central and the lateral section respectively. As expected, after the cavity excavation, the central roof section is the most loaded one exhibiting the lowest value of FoS.

Starting from this stress distribution induced by the cavity excavation, thus from this initial equilibrium condition, the seismic excitation starts, producing in the surrounding cavity a continuous redistribution of the stresses during ground shaking. As example of the time history of ${ }_{x x}$ in some points of the cavity roof- selected each $1 \mathrm{~m}$ along the central and the right sections of the roof beam -is shown in Figure 3, 


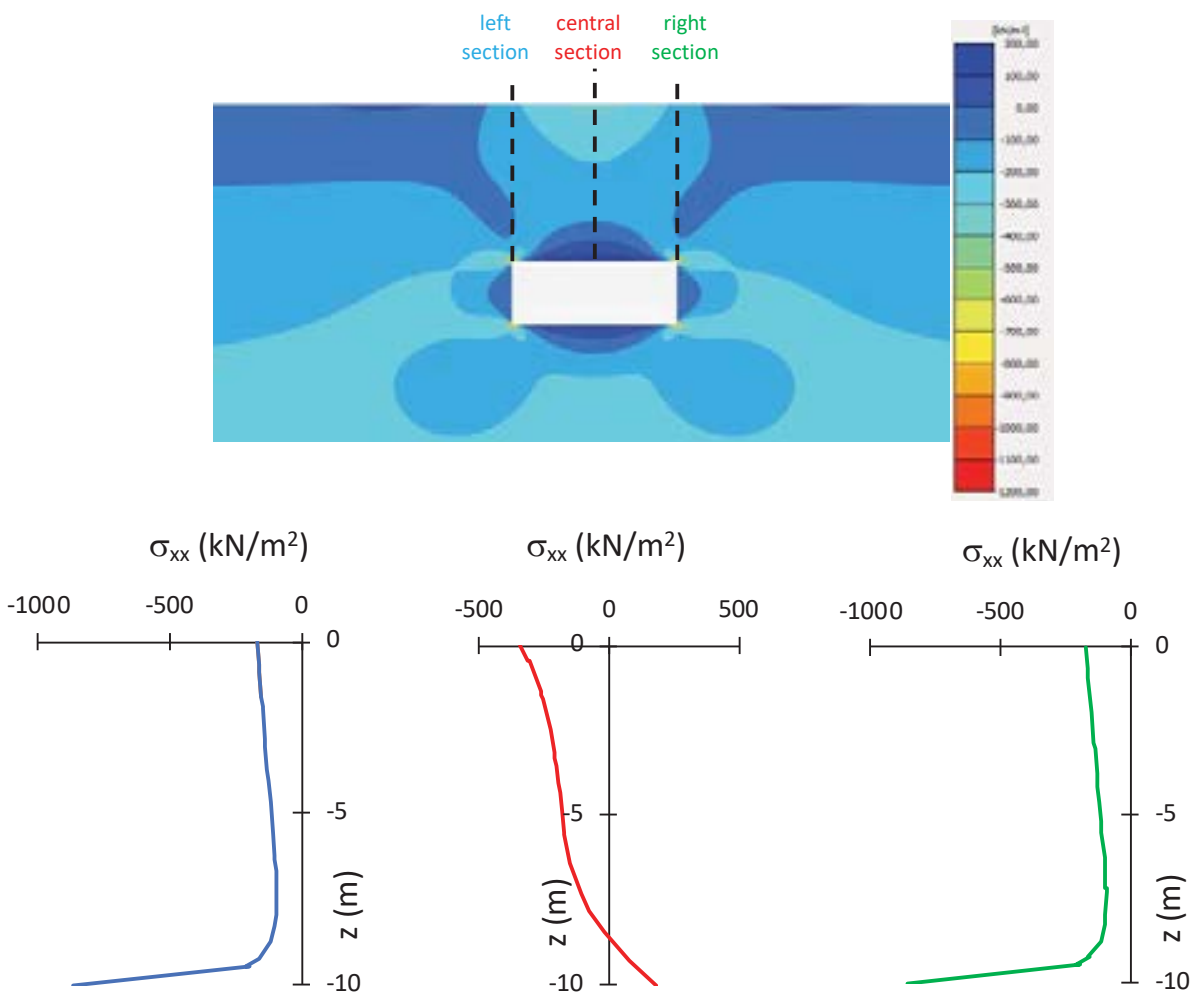

Figure 2: Horizontal stress distribution after the cavity (layout \#3.1) excavation.

Consistently with the expected ground deformation under shaking, the lateral sections of the cavity roof experience higher stress variation than the central section. This implies a different modification of the FoS in the considered sections during shaking.

In the central section, starting from $\mathrm{FoS}_{\text {static }}=4$, a minimum value of $\mathrm{FoS}_{\mathrm{dyn} \text { min }}=3.6$ occurred at the instant $\mathrm{t}=6.15 \mathrm{~s}$ of the time history and a value of $\mathrm{FoS}_{\mathrm{dyn} \text { final }}=4.3$ is computed at the end of the shaking; in the left and right sections, starting from $\mathrm{FoS}_{\text {static }}=12$, a minimum value of $\mathrm{FoS}_{\mathrm{dyn} \min }=1.6$ occurred at the instant $\mathrm{t}=6.15 \mathrm{~s}$ of the time history and a value of $\mathrm{FoS}_{\mathrm{dyn} \_ \text {final }}=8$ is computed at the end of the shaking.

Therefore, the initial static conditions of the central section do not change substantially during the shaking, actually a slight increase of FoS occurs at the end shaking due to the redistribution of stress. Such aspect was already observed with reference to a more complex case study by [10]. Conversely, an important reduction of FoS is observed in the lateral sections both during and at the end of the shaking (a reduction of $\mathrm{FoS}_{\text {static }}$ about equal to $86 \%$ and $25 \%$ is calculated respectively) due to the high seismic intensity of the selected earthquake, highlighting the effect of earthquake-induced modifications of the static equilibrium under gravity loads. Fortunately, the FoS after earthquake increases in the section (the central) where $\mathrm{FoS}_{\text {static }}$ was lower and does not reduce down to unity in the lateral sections, hence the roof stability of the selected cavity is not compromised. 


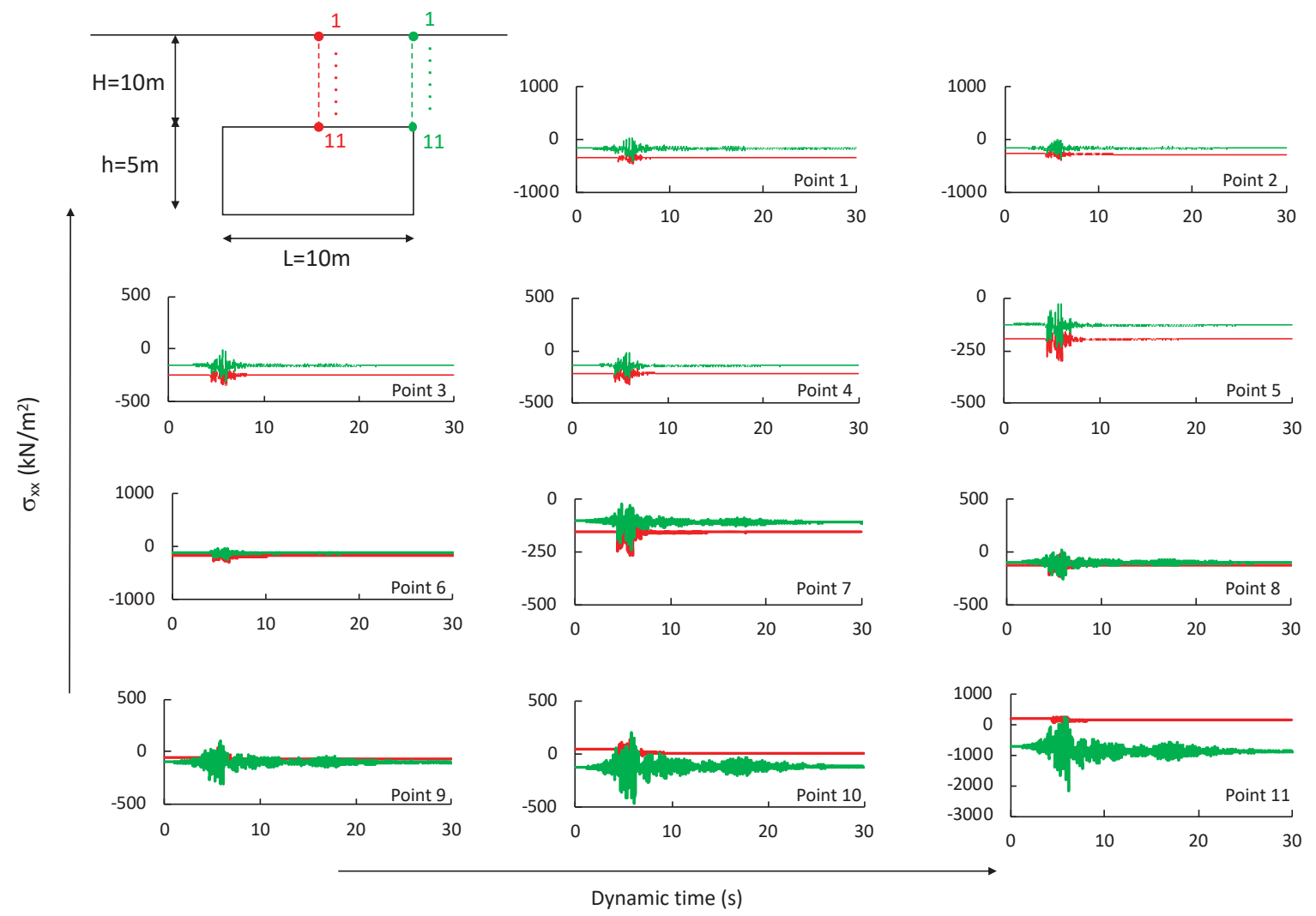

Figure 3: Horizontal stress time history in correspondence of selected points of the cavity roof (layout \#3.1) during Loma Prieta earthquake 1989 earthquake.

To generalize the outcome of the proposed parametric study, the FoS values calculated for all cases as the minimum between the central and lateral sections, were processed as function of the increasing intensity of PGA in the proposed Seismic Stability Charts for Cavities, SSCCs (Figure 4). Each chart refers to a specific cavity geometry including both considered loading combinations ( $\mathrm{q}_{1}$ black lines/points, $\mathrm{q}_{2}$ grey lines/points). In particular, the first row of Figure 4 represents the three cases in which $\mathrm{H}$ is set equal to $2 \mathrm{~m}$ while $\mathrm{L}$ varies from $2 \mathrm{~m}$ to $10 \mathrm{~m}$ (Figs 4a,b,c respectively), the second row of Figure 4 represents the four cases in which $\mathrm{H}$ is set equal to $5 \mathrm{~m}$ while L varies from $5 \mathrm{~m}$ to $20 \mathrm{~m}$ (Figs 4d,e,f,g respectively), the third row of Figure 4 represents the three cases in which $\mathrm{H}$ is set equal to $10 \mathrm{~m}$ while $\mathrm{L}$ varies from $10 \mathrm{~m}$ to $20 \mathrm{~m}$ (Figs $4 \mathrm{~h}, \mathrm{i}, \mathrm{j}$ respectively).

The general trend of the results shown in the figure leads to the following considerations:

1. FoS tends to decrease with the increasing of the seismic loading intensity, here expressed as function of PGA;

2. higher FoS is expected for $\mathrm{q}_{1}$ loading combination compared to $\mathrm{q}_{2}$, because a lower vertical stress is initially induced by a lower overburden; however, with increasing cavity depth such effect vanishes as expected;

3. shallower (lower depth $H$ with same width $L$ ) and wider (larger width $L$ with same depth $\mathrm{H})$ cavities exhibit a lower level of safety (FoS) compared with the deeper and narrower ones, when the seismic intensity (PGA) increases. 


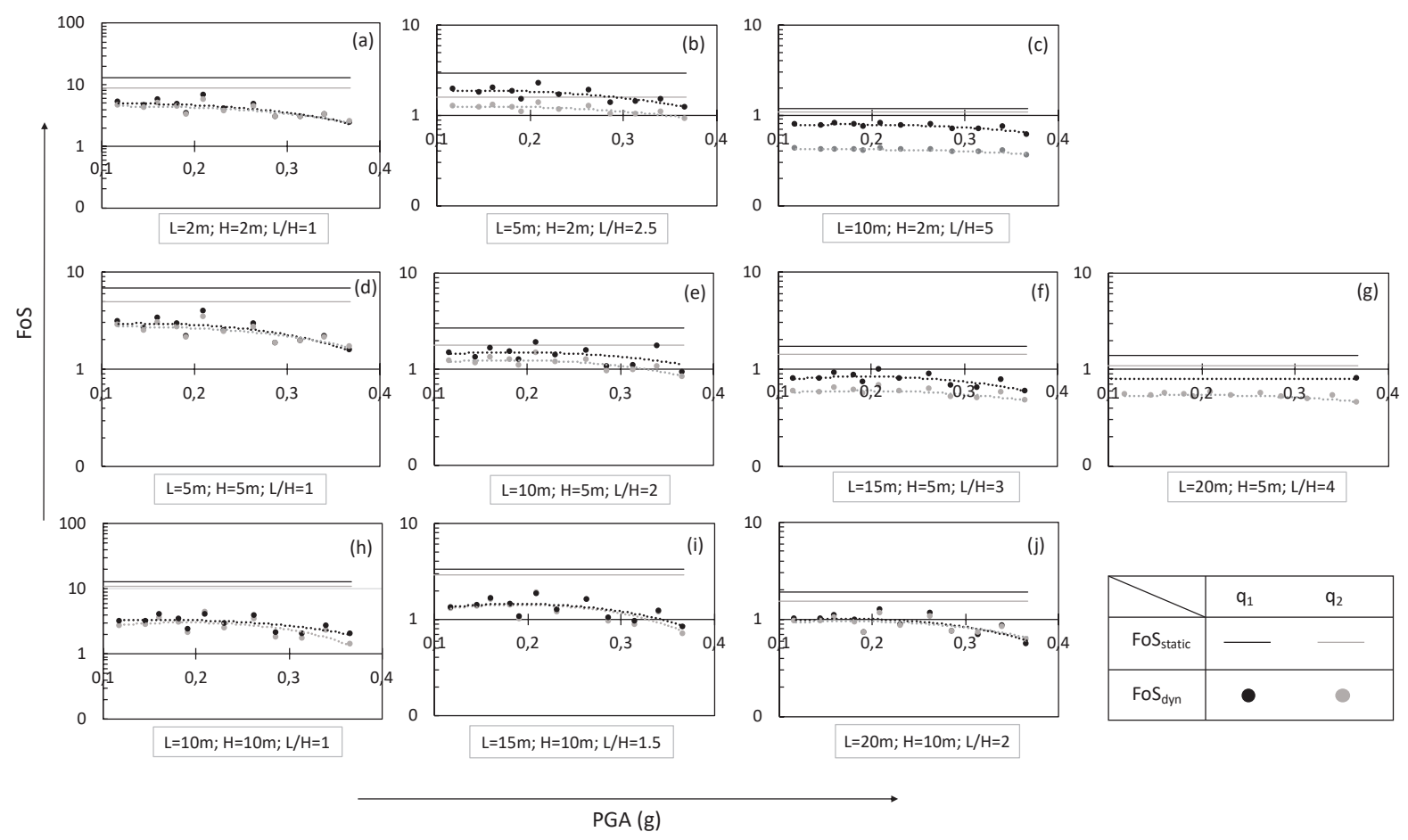

Figure 4: Seismic Stability Charts for Cavities (SSCCs) when $\mathrm{H}=2 \mathrm{~m}(\mathrm{a}, \mathrm{b}, \mathrm{c}), \mathrm{H}=5 \mathrm{~m}(\mathrm{~d}, \mathrm{e}, \mathrm{f}, \mathrm{g}), \mathrm{H}=10 \mathrm{~m}(\mathrm{~h}, \mathrm{i}, \mathrm{j})$.

It is worth noting that, for the considered layouts, instability conditions (i.e. $\mathrm{FoS}<1$ ) are achieved, independently of the amplitude of the input motion, when $\mathrm{H}=2 \mathrm{~m}$ and $\mathrm{L} / \mathrm{H}>5, \mathrm{H}=5$ $m$ and $L / H>3$, while failure occurs only under the highest PGA when $H=10 \mathrm{~m}$ and $\mathrm{L} / \mathrm{H}>1.5$.

The proposed charts can be adopted as a preliminary level of screening to assess the seismic vulnerability of shallow underground cavities in soft rock, by comparing the so calculated FoS values with a threshold expressing the accepted damage level (i.e. the well-known limit state): "damage limit state" occurring when the FoS is lower than 3; "collapse limit state" associated to FoS lower than 1.5 [10]. In this way, a reconnaissance of possible critical zones that need a more detailed and site-specific analysis can be accomplished.

However, the basic hypotheses of the present study - that constrain the use of the proposed charts to a specific field of applicability - should be here underlined: i) the charts are valid for cavities with approximate flat roof, which are the most widespread in urban areas, hence their applications to arch roof could lead to an underestimation of FoS; ii) the charts are valid in presence of cavity excavated into a homogeneous lithotype rock, therefore they are not strictly applicable in presence of multiple lithotypes that may imply different site effects [15]. Any simplification in the use of the proposed charts outside the hypotheses under which they were obtained, can reduces their reliability.

\section{CONCLUSIONS}

The seismic actions represent a source of instability for underground cavities, bringing to their damage up to the global collapse. This possibility represents matter of concern leading to potential risk situations for buildings, infrastructures and population. In this scenario the present work represents an attempt to frame the problem at large scale, proposing a methodologi- 
cal approach that provides stability charts to assess the seismic vulnerability of shallow underground cavities in soft rock, as preliminary level of screening.

The charts evaluate the cavity seismic stability by means of the proposed Factor of Safety ( $\mathrm{FoS}=\mathrm{M}_{\mathrm{r}, \mathrm{ULS}} / \mathrm{M}_{\text {load }}$ of the most vulnerable roof beam sections) as a function of some controlling parameters: the width of the cavity, the depth of the cavity roof, the PGA of the earthquake and the overburden stress on the top of the rock layer. By comparing the estimated FoS values with threshold values expressing the admissible damage level, possible instable cavities can be identified, that require a detailed site analysis.

The discussed results represent a preliminary outcome of a larger ongoing research project that is aimed to extend the methodological approach proposed in this paper to study a large number of cases, including different geometrical layouts and rock mechanical characteristics, in order to widen the applicability of the proposed charts.

\section{ACKNOWLEDGEMENT}

This research was supported by the Italian Civil Protection Department within the project "Contratto concernente l'affidamento di servizi per il programma per il supporto al rafforzamento della Governance in materia di riduzione del rischio sismico e vulcanico ai fini di protezione civile nell'ambito del PON Governance e Capacita Istituzionale 2014-2020 CIG6980737E65".

\section{REFERENCES}

[1] Evangelista L, de Silva F, d'Onofrio A, et al. Application of ERT and GPR geophysical testing to the subsoil characterization of cultural heritage sites in Napoli (Italy). Measurement. 2016;104:326-335.

[2] Santo A., Ascione A., Del Prete S., Di Crescenzo G., Santangelo N. (2011) Collapse sinkholes distribution in the carbonate massifs of Central and Southern Apennines. Acta Carsologica 40 (1), 95-112. https://doi.org/10.3986/ac.v40i1.31.

[3] Guidoboni E., Ferrari G., Tarabusi G., Sgattoni G., Comastri A., Mariotti D., Ciuccarelli C., Bianchi M.G., Valensise G. (2019) CFTI5Med, the new release of the catalogue of strong earthquakes in Italy and in the Mediterranean area. Scientific Data 6, 80. doi: https://doi.org/10.1038/s41597-019-0091-9.

[4] Fortunato C., Martino S., Prestininzi A., Romeo R.W., coauthors Fantini A., Sanandrea P. (2012) New release of the Italian catalogue of earthquake-induced ground failures (CEDIT). Italian Journal of Engineering Geology and Environment, DOI: 10.4408/IJEGE.2012-02.O-05.

[5] Evangelista A., Feola A., Flora A., Lirer S., Maiorano R.M.S. (2000) Numerical analysis of roof failure mechanisms in a soft rock. GEOEng 2000. Melbourne.

[6] Evangelista A, Flora A, Lirer S, de Sanctis F, Lombardi G. Studi ed interventi per la tutela di un patrimonio sotterraneo: l'esempio delle cavità di Napoli. In: Proceedings of 21st Geotechnical National Conference. L'Aquila; 11-14 September 2002. p. 579-588 [in Italian]. 
[7] Scotto di Santolo A, Evangelista L, Silvestri F, et al. (2015) Investigations on the stability conditions of a tuff cavity: the Cimitero delle Fontanelle in Napoli. Riv Ital di Geotec. 2015:28-46.

[8] Scotto di Santolo A, Evangelista L, Evangelista A. Analysis of the stability of a rock cavern: the Fontanelle cemetery. In: Lollino G, Giordan D, Marunteanu C, Christaras B, Yoshinori I, Margottini C, eds. Engineering Geology for Society and Territory. Cham: Springer; 2015.; 8.

[9] de Silva F., Scotto di Santolo A. (2018) Probabilistic performance-based approaches to the static and seismic assessment of rock cavities. International Journal of Rock Mechanics and Mining Sciences 112 (2018) 354-368.

[10] de Silva F., Scotto di Santolo A. (2020) Post-earthquake resilience of a room and pillar rock cavity in Naples. In: Calvetti F., Cotecchia F., Galli A., Jommi C. (eds) Geotechnical Research for Land Protection and Development. CNRIG 2019. Lecture Notes in Civil Engineering, vol 40. 229-308. Springer, Cham.

[11] Vinale F. Caratterizzazione del sottosuolo di un'area campione di Napoli ai fini della microzonazione sismica. Riv Ital Geotec. 1988;22(3):77 - 100 [in Italian].

[12] Fabozzi S., Bilotta E., Russo G. (2016). Numerical interpretation of monitoring data of an instrumented tunnel segmental ring. $1^{\circ}$ IMEKO-TC4 International Workshop on Metrology for geotechnics. MetroGeotechnics 2016 pp. 350-355. Benevento, Italy / March 17-18, 2016.

[13] Fabozzi S., Licata V., Autuori S., Bilotta E., Russo G., Silvestri F. (2017) Prediction of the seismic behavior of an underground railway station and a tunnel in Napoli (Italy). Underground Space 2 (2017) 88-105. http://dx.doi.org/10.1016/j.undsp.2017.03.05.

[14] Kuhlemeyer R.L and Lysmer J. (1973) Finite Element Method Accuracy for Wave Propagation Problems. Journal of the Soil Mechanics and Foundation Division, 99(5), 421- 427.

[15] Fabozzi S., Catalano S., Falcone G., Pagliaroli A., Peronace E., Porchia A., Romagnoli G., Moscatelli M. (2021) Stochastic approach to study the site response in presence of shear wave velocity inversion: application to seismic microzonation studies in Italy. Engineering Geology 280 (2021) 105914 https://doi.org/10.1016/j.enggeo.2020.105914. 